\title{
Cervical and axial dystonia in a patient with syringomyelia
}

Distonia cervical e axial em uma paciente com siringomielia

Francisco Pereira da Silva-Júnior', Jasper Guimarães Santos', Flávio Augusto Sekeff-Sallem', Leandro

Tavares Lucato², Egberto Reis Barbosa ${ }^{1}$

'Department of Neurology of Universidade de São Paulo (USP), São Paulo SP, Brazil;

2Department of Radiology of USP, São Paulo SP, Brazil.

Correspondence: Francisco Pereira da Silva-Júnior; Rua Doutor Melo Alves 55 / apto. 123; 01417-010 São Paulo SP - Brasil; E-mail: franciscops@hotmail.com Conflict of interest: There is no conflict of interest to declare.

Received 15 April 2012; Received in final form 27 April 2012; Accepted 04 May 2012

Abnormal electromyographic activity is commonly found in patients with syringomyelia, but involuntary movements have only rarely been reported ${ }^{1}$.

We have reported the case of a patient with large syringomyelia, who developed cervical and axial dystonia.

\section{CASE REPORT}

A 40-year-old woman presented with progressive sensory loss and weakness of the lower limbs, followed by urinary retention. Concomitantly, she developed repetitive 
painful involuntary movements of the head, neck, and thoracolumbar region.

Her history was remarkable for pulmonary and meningeal tuberculosis at the age of 35 years. In that occasion, she discovered to be HIV positive.

Neurologic examination revealed reduced pinprick, touch and temperature sensation to the level of $\mathrm{C}_{4}$ on the right, and $\mathrm{T}_{2}$ on the left side of the body. Vibration and joint position senses were absent in the lower limbs, which were plegic and atrophic. Deep tendon reflexes were normal in the upper and absent in the lower extremities. Involuntary jerky movements, primarily consisting of retrocollis and thoracolumbar extension were noticed. Mental status and cranial nerves were normal.

Laboratory evaluation was unremarkable. Brain magnetic resonance imaging (MRI) was normal. Cervical and thoracic MRI disclosed a large septated syringomyelia extending from the cervicothoracic junction to the conus medullaris, with evidence of arachnoid adhesions (Figure). The electromyography showed cervical and axial dystonia.

The patient underwent a $\mathrm{T}_{4-6}$ laminectomy with syringesubarachnoid shunt. Her neurologic condition remained unchanged two years after the surgery. She received botulinum toxin A in the splenius capitis, deep cervical paraspinal, and thoracolumbar paravertebral muscles bilaterally. She experienced marked improvement of the involuntary movements and pain.

\section{DISCUSSION}

The patient presented cervical and axial dystonia concomitantly with the onset of progressive neurological signs, which led to syringomyelia diagnosis.

Syringomyelic dystonia has been rarely reported and included cases with torcicollis ${ }^{1,2}$, dystonia of the legs ${ }^{3}$, dystonia of the hands and $\mathrm{arms}^{4}$, cervical dystonia ${ }^{4}$, and blefarospasm ${ }^{1}$.

The mechanisms of involuntary movements secondary to spinal cord lesions have yet to be fully understood.

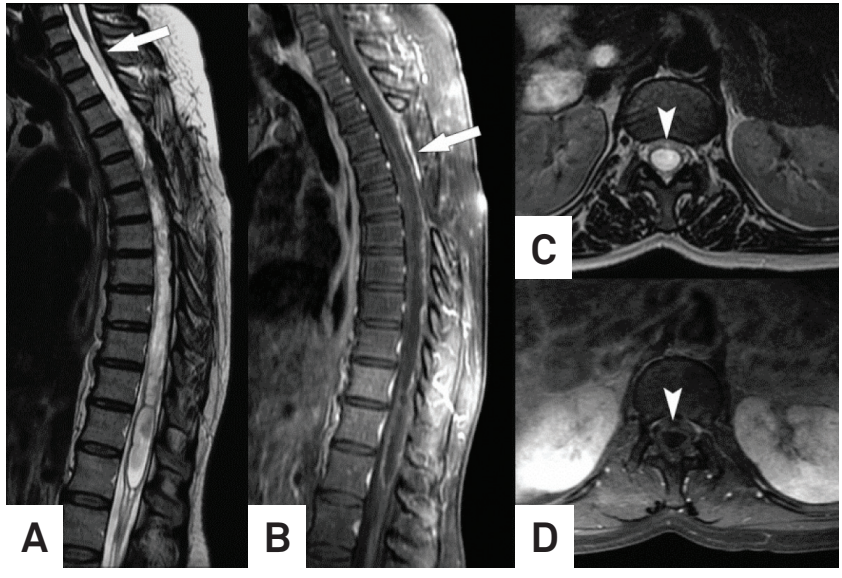

Figure. Sagittal $T_{2}$-weighted image (A) demonstrates focal thinning of the spinal cord in the cervicothoracic junction (arrow). There is some indistinction of the cord in the superior thoracic level, and caudally one can appreciate a multiloculated syrinx cavity that extends to the conus medullaris. Sagittal postgadolinium $\mathrm{T}_{1}$-weighted image $(\mathrm{B})$ depicts the area of surgical manipulation (arrow), immediately below the cord thinning cited above; there is, in this location, also some pachymeningeal enhancement, probably surgery-related. In this image, it is clear that meningeal adherences in this area are presumably causing the syrinx cavity that reaches the conus. Axial $T_{2}(C)$ and postgadolinium $T_{1}$-weighted (D) images show the syrinx cavity in more details (arrowheads).

Electrophysiological findings suggest a role for damage of $\alpha$-motor neuron, lesion of spinal interneurons, and damage to descending motor pathways ${ }^{1}$.

Few cases of syringomyelia as a complication of tuberculous meningitis have been described. There is usually a latent period between the evidence of inflammation and the development of syringomyelic symptoms, which varies between 7 to 28 years. In these cases, arachnoid adhesions and multifocal loculations were often present, which resulted in treatment failures and poor prognosis ${ }^{5}$.

We described a rare case of dystonia associated with syringomyelia, highlighting the involvement of spinal cord lesions in the genesis of involuntary movements and reinforcing the importance of obtaining a spinal cord MRI when investigating a case of dystonia with atypical presentation.

\section{References}

1. Nogués MA, Leiguarda RC, Rivero AD, Salvat F, Manes F. Involuntary movements and abnormal spontaneous EMG activity in syringomyelia and syringobulbia. Neurology 1999;52:823-834.

2. Kiwak KJ, Deray MJ, Shields D. Torcicollis in three children with syringomyelia and spinal cord tumor. Neurology 1983;33:946-948.

3. Berardelli A, Thompson PD, Day BL, Rothwell JC, O'Brien MD, Marsden $\mathrm{CD}$. Dystonia of the legs induced by walking or passive movement of the big toe in a patient with cerebellar ectopia and syringomyelia. Neurology 1986;36:40-44.

4. Hill MD, Kumar R, Lozano A, Tator CH, Ashby P, Lang AE. Syringomyelic dystonia and athetosis. Mov Disord 1999;14:684-688.

5. Kaynar MY, Koçer N, Gençosmanoğlu BE, Hanci M. Syringomyeliaas a late complication of tuberculous meningitis. Acta Neurochir 2000;142:935-939. 